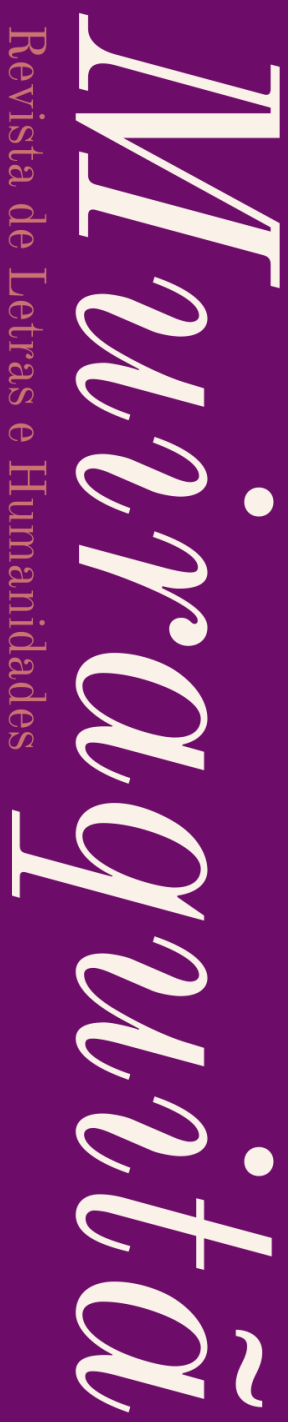

\title{
Entre fronteiras, matas e beiras de rios: Amazônia legal brasileira e o pesquisar da educação escolar indígena
}

\author{
Leni Feitosa \\ Universidade Federal do Tocantins \\ lenifeitosa@hotmail.com \\ https://orcid.org/0000-0001-7333-5264 \\ Idemar Vizolli \\ Universidade Federal do Tocantins \\ idemar@mail.uft.edu.br \\ https://orcid.org/0000-0002-7341-7099
}

RESUMO: O artigo objetiva verificar enfoques e contribuições de pesquisas brasileiras vinculadas aos programas de pós-graduação em educação que tematizam a educação escolar indígena na Amazônia Legal brasileira no período de 2010 a 2019, à luz do estado do conhecimento. A busca ocorreu no repositório de Catálogo de Teses e Dissertações da Coordenação de Aperfeiçoamento de Pessoal de Nível Superior. Foram encontradas 3.550 teses e 10.491 dissertações, e, após refinamento de busca, chegou-se ao corpus da pesquisa com 5 teses e 10 dissertações. As pesquisas possuem vários enfoques: práticas pedagógicas de professores indígenas, processos educativos, projeto político pedagógico, processo de escolarização, aquisição da língua portuguesa, aspirações do futuro de comunidade indígena, políticas indigenistas, conexão com a educação indígena, ressignificação do ambiente escolar colonialista e políticas públicas no âmbito municipal. As contribuições confluem no pensar e fazer uma educação escolar diferenciada em territórios indígenas na Amazônia Legal brasileira.

PALAVRAS-CHAVE: Educação. Amazônia brasileira. Educação escolar indígena. Programa de pósgraduação em educação. Estado do conhecimento.

\section{BETWEEN FRONTIERS, FORESTS AND RIVERS EDGES: BRAZILIAN LEGAL AMAZON AND THE RESEARCH OF INDIGENOUS SCHOOL EDUCATION}

ABSTRACT: The article aims to verify approaches and contributions of Brazilian research linked to postgraduate programs in education that focus on indigenous school education in the Brazilian Legal Amazon from 2010 to 2019, in light of the state of knowledge. The search took place in the Theses and Dissertations Catalog repository of the Coordenação de Aperfeiçoamento de Pessoal de Nivel Superior. A total of 3,550 theses and 10,491 dissertations were found, and after refining the search, the research corpus was reached with 5 theses and 10 dissertations. The researches have several focuses: pedagogical practices of indigenous teachers, educational processes, political pedagogical project, schooling process, acquisition of the Portuguese language, aspirations for the future of the indigenous community, indigenous policies, connection with indigenous education, resignification of the colonialist school environment, and public policies at the municipal level. The contributions come together in thinking about and carrying out a differentiated school education in indigenous territories in the Brazilian Legal Amazon.

KEYWORDS: Education. Brazilian legal Amazon. Indigenous school education. Graduate program in education. State of knowledge. 


\section{INTRODUÇÃO}

Possuindo uma dimensão internacional com uma superfície de mais de 7 milhões de $\mathrm{km}^{2}$, a Amazônia, localizada na América do Sul, referida também como Pan-Amazônia, Amazônia continental, Amazônia sul-americana e Grande Amazônia, é compartilhada em territórios de 8 países, e 1 departamento francês, respectivamente, Brasil $(67,98 \%)$, Bolívia (5,31\%), Peru (10,14\%), Equador (1,55\%), Colômbia (6,40\%), Venezuela (2,45\%), Guiana $(2,87 \%)$, Suriname $(2,18)$ e Guiana Francesa $(1,12 \%)$ (ARAGÓN, 2018).

No vislumbre mundial, é classificada como a maior floresta tropical úmida do planeta, possuindo a maior bacia hidrográfica, maior reserva de biodiversidade e banco genético, bem como uma das mais ricas províncias minerais (MELO, 2013).

A Amazônia Legal brasileira (ALB) perfaz uma extensão territorial de 5.015.067,749 $\mathrm{km}^{2}$, correspondente a 58,9\% do território brasileiro, compartilhada com os sete estados da região norte: Acre, Amazonas, Amapá, Pará, Rondônia, Roraima e Tocantins; um estado da região centro oeste: Mato Grosso, e um estado da região nordeste, Maranhão ${ }^{1}$ (IBGE, 2021).

Na ALB há uma imensa diversidade étnica, cultural, territorial e populacional indígena. Segundo Heck, Loebens e Carvalho (2005), a Amazônia indígena brasileira representa $23 \%$ do território amazônico, compartilhada com 180 povos, além de vários grupos isolados $^{2}$, que habitam entre fronteiras, rios e matas em 436 territórios, correspondente, de acordo com informações do Instituto Socioambiental, a 98,25\% da extensão de todas as terras indígenas do país.

Os povos indígenas na ALB perfazem uma população de 433.417 indígenas, representando 48,32\% da população indígena brasileira (IBGE, 2010). Têm-se no Quadro 1, o vislumbre, por Unidade Federativa (UF), do número de Terra Indígena (TI), área das Terras Indígenas, bem como a população indígena (PI) que compartilham a ALB.

Quadro 1- Terras indígenas, área e população indígena por unidade federativa que compartilham a ALB

\begin{tabular}{|l|c|c|c|c|c|}
\hline \multicolumn{1}{|c|}{ UF } & TI $^{*}$ & Área de TI** & $\begin{array}{c}\text { \% área da } \\
\text { TI }\end{array}$ & $\begin{array}{c}\text { População } \\
\text { indígena*** }^{* * 1}\end{array}$ & \% PI \\
\hline Acre & 36 & 2.459 .834 & 14,92 & 17.578 & 4,06 \\
\hline Amapá & 6 & 1.191 .343 & 8,06 & 7.411 & 1,71 \\
\hline Amazonas & 163 & 45.232 .159 & 28,54 & 183.514 & 42,35 \\
\hline Maranhão & 23 & 2.285 .329 & 8,63 & 38.831 & 8,96 \\
\hline Mato Grosso & 87 & 15.022 .842 & 16,57 & 51.696 & 11,93 \\
\hline Pará & 67 & 28.687 .362 & 22,89 & 51.271 & 11,82 \\
\hline Rondônia & 6 & 5.022 .789 & 21,05 & 13.076 & 3,02 \\
\hline Roraima & 34 & 10.370 .676 & 46,20 & 55.922 & 12,90 \\
\hline Tocantins & 14 & 2.597 .580 & 9,33 & 14.118 & 3,26 \\
\hline & & & & & \\
\hline
\end{tabular}

Fonte: Elaborado pelos autores, a partir de informações da FUNAI (2021)*, ISA (2014) ** e IBGE (2010) ***

\footnotetext{
1 Apenas parte do estado do Maranhão compõe a ALB, cerca de $34 \%$ do território, equivalente a $81.208,40 \mathrm{~km}^{2}$, englobando 62 municípios num prolongamento que parte do Rio Gurupi, na cidade de Carutapera chega em São Luís, passa por Santa Inês, Formosa da Barra Negra e alcança a cidade Carolina (SECRETARIA, 2021).

2 Refere-se especificamente a grupos indígenas com ausência de relações permanentes com as sociedades nacionais ou com pouca frequência de interação, seja com não-índios, seja com outros povos indígenas (FUNAI, 2021).
} 
O maior número de terra, área e população indígena situam-se no Amazonas. Nota-se a proeminência de Roraima quanto ao percentual da área de terra indígena em relação à área da unidade federativa. No que tange à população indígena, tem-se, nesta ordem, Amazonas, Roraima, Mato Grosso, Pará, Maranhão, Acre, Tocantins, Rondônia e Amapá.

No território brasileiro, os povos indígenas têm direito a uma educação escolar diferenciada, específica, bilíngue/multilíngue e intercultural, princípios substanciados na legislação nacional que regulamenta a Educação Escolar Indígena alinhada à Constituição Federal de 1988 e Lei de Diretrizes e Bases da Educação Nacional de 1996.

Grupioni (2003) menciona que nas últimas décadas, os estudos sobre educação escolar indígena têm sido evidenciados por pesquisadores que tratam da temática indígena, sobretudo da educação escolar em seus territórios. Situação que o autor associa à expansão dos programas de pós-graduação nas universidades brasileiras; à ação de movimentos sociais que demarcam interesses, identidades e subjetividades dos povos indígenas; a experiências de educação indígena diferenciada; e a legislações educacionais específicas que seguem a atual Lei de Diretrizes e Bases da Educação Nacional (LDB).

À vista disso, Grupioni (2003, p. 197) ainda esclarece que a veemência pela temática educação escolar indígena é substanciada pela "importância da escola para os próprios povos indígenas, uma vez que se tornou uma questão social e politicamente importante para eles e para aqueles que os apoiam". Assim, ao compreendermos a diversidade étnica, cultural, territorial e populacional indígena na ALB, nos desafiamos a realizar esta investigação científica para responder a inquire: o que revelam as pesquisas brasileiras vinculadas aos programas de pós-graduação em educação que tematizam a educação escolar indígena na ALB? Nesse vislumbre, este artigo verifica enfoques e contribuições de pesquisas brasileiras vinculadas aos programas de pós-graduação em educação que tematizam a educação escolar indígena na ALB no período de 2010 a 2019, à luz do estado do conhecimento.

\section{ANDARILHAR DA COMPOSIÇÃO DO CORPUS DA PESOUISA}

À luz do estado do conhecimento, que permite realizar mapeamento e análise de produções acadêmicas com vista na elaboração de novos conhecimentos, o estudo caracteriza-se como bibliográfico, descritivo e analítico. O levantamento tem recorte temporal e espacial, respectivamente, 2010 a 2019 e produções acadêmicas brasileiras. A busca ocorreu no repositório de Catálogo de Teses e Dissertações da Coordenação de Aperfeiçoamento de Pessoal de Nível Superior (CAPES), vinculada à Plataforma Sucupira, base de referência do Sistema Nacional de Pós-Graduação do Brasil ${ }^{3}$.

Para a busca, foram utilizados quatro descritores":"educação escolar indígena" + "escolarização indígena" +"escola indígena" +"Amazônia", resultando 3.550 teses e

3 A busca de produções acadêmicas, teses e dissertações, ocorreu no dia 03 de janeiro de 2021, no endereço eletrônico: http://catalogodeteses. capes.gov.br/catalogo-teses/\#!/.

4 Ressalta-se que em nenhuma das produções acadêmicas constam todos os descritores de busca, conquanto o descritor "educação escolar indígena" inclui-se em todas as pesquisas que constitui o corpus deste estudo. 
10.491 dissertações. A partir desse número, aplicamos dois filtros: área de conhecimento e concentração, ambas com enquadramento em Educação, sucedendo 79 teses e 259 dissertações.

Procedemos ainda com mais três refinamentos: leitura dos títulos, palavras-chave e resumos, vislumbrando nessa ordem: 12 teses e 34 dissertações; 11 teses e 25 dissertações; e 5 teses e 10 dissertações. Ao alinhar-se ao escopo da pesquisa, o corpus foi constituído por 5 teses e 10 dissertações, sistematizado no Quadro 2, com informações de autoria, título da produção acadêmica e instituição a qual está vinculada.

Quadro 2 - Corpus de pesquisa, dissertações e teses que tematizam a educação escolar indígena na ALB, 20132018

\begin{tabular}{|c|c|c|}
\hline $\begin{array}{l}\text { Autor (a)/Ano } \\
\text { Tese/Dissertação }\end{array}$ & Título & Instituição \\
\hline $\begin{array}{l}\text { Abbonizio (2013) } \\
\text { Tese }\end{array}$ & $\begin{array}{l}\text { Educação escolar indígena como inovação educacional: a } \\
\text { escola e as aspirações de futuro das comunidades }\end{array}$ & $\begin{array}{l}\text { Universidade de São } \\
\text { Paulo }\end{array}$ \\
\hline $\begin{array}{l}\text { Neto (2013) } \\
\text { Dissertação }\end{array}$ & $\begin{array}{l}\text { Educação escolar indígena Mura: por entre práticas docen- } \\
\text { tes e o Projeto Político-Pedagógico }\end{array}$ & $\begin{array}{l}\text { Universidade Federal do } \\
\text { Amazonas }\end{array}$ \\
\hline $\begin{array}{l}\text { Abreu (2014) } \\
\text { Dissertação }\end{array}$ & $\begin{array}{l}\text { A implementação do direito à educação escolar indígena } \\
\text { no município de Santarém no período de } 2006 \text { a } 2012\end{array}$ & $\begin{array}{c}\text { Universidade Federal do } \\
\text { Pará }\end{array}$ \\
\hline $\begin{array}{l}\text { Bastos (2014) } \\
\text { Tese }\end{array}$ & $\begin{array}{l}\text { Educação escolar indígena na região do Uaçá no município } \\
\text { de Oiapoque-AP (1964-1985) }\end{array}$ & $\begin{array}{l}\text { Universidade Federal de } \\
\text { Uberlândia }\end{array}$ \\
\hline $\begin{array}{l}\text { Santos (2014) } \\
\text { Dissertação }\end{array}$ & $\begin{array}{l}\text { As políticas educacionais e seus impactos na educação indí- } \\
\text { gena: um estudo nas comunidades pertencentes ao municí- } \\
\text { pio de Guajará-Mirim/RO }\end{array}$ & $\begin{array}{l}\text { Universidade Federal de } \\
\text { Rondônia }\end{array}$ \\
\hline $\begin{array}{l}\text { Castro (2015) } \\
\text { Dissertação }\end{array}$ & $\begin{array}{l}\text { Tecendo novos olhares para a educação escolar indígena: } \\
\text { a escola diferenciada Huni Kuin na Região do Breu e seus } \\
\text { atores }\end{array}$ & $\begin{array}{l}\text { Universidade Estadual de } \\
\text { Campinas }\end{array}$ \\
\hline $\begin{array}{l}\text { Prates (2016) } \\
\text { Dissertação }\end{array}$ & $\begin{array}{c}\text { O Ensino de Arte na Escola Indígena Bororo Korogedo } \\
\text { Paru da Aldeia Córrego Grande - MT }\end{array}$ & $\begin{array}{l}\text { Universidade Federal de } \\
\text { Mato Grosso }\end{array}$ \\
\hline $\begin{array}{l}\text { Rodrigues (2016) } \\
\text { Tese }\end{array}$ & $\begin{array}{c}\text { Surara Borari, Surara Arapium. A educação escolar no } \\
\text { processo de reafirmação étnica dos Borari e Arapium da } \\
\text { Terra Indígena Maró }\end{array}$ & $\begin{array}{l}\text { Universidade Estadual de } \\
\text { Campinas }\end{array}$ \\
\hline $\begin{array}{l}\text { Câncio (2017) } \\
\text { Tese }\end{array}$ & $\begin{array}{l}\text { Para além da aldeia e da escola: um estudo decolonial de } \\
\text { aquisição da língua portuguesa pelos indígenas Wai-Wai da } \\
\text { aldeia Mapuera, Amazônia Brasileira }\end{array}$ & $\begin{array}{l}\text { Universidade Federal do } \\
\text { Pará }\end{array}$ \\
\hline $\begin{array}{l}\text { Corezomaé (2017) } \\
\text { Dissertação }\end{array}$ & $\begin{array}{l}\text { Educação escolar do povo indígena Balatiponé-Umutina: } \\
\text { compreendendo processos educativos da escola Julá Paré }\end{array}$ & $\begin{array}{l}\text { Universidade Federal de } \\
\text { São Carlos }\end{array}$ \\
\hline $\begin{array}{l}\text { Mendes (2017) } \\
\text { Dissertação }\end{array}$ & $\begin{array}{c}\text { Educação escolar indígena Paiter Suruí e sua relação com } \\
\text { os etnoconhecimentos }\end{array}$ & $\begin{array}{l}\text { Universidade do Estado } \\
\text { de Mato Grosso }\end{array}$ \\
\hline $\begin{array}{l}\text { Cunha (2018) } \\
\text { Tese }\end{array}$ & $\begin{array}{l}\text { Luzes apagadas: a educação escolar indígena na Amazônia } \\
\text { colonial }\end{array}$ & $\begin{array}{l}\text { Universidade de São } \\
\text { Paulo }\end{array}$ \\
\hline $\begin{array}{l}\text { Feitosa (2018) } \\
\text { Dissertação }\end{array}$ & $\begin{array}{l}\text { Da flecha à caneta: Escolarização indígena Mẽbêngôkre } \\
\text { Gorotire }\end{array}$ & $\begin{array}{l}\text { Universidade Federal do } \\
\text { Tocantins }\end{array}$ \\
\hline $\begin{array}{l}\text { Paula (2018) } \\
\text { Dissertação }\end{array}$ & $\begin{array}{l}\text { Escola Apyãwa: da vivência e convivência da educação } \\
\text { indígena à educação escolar intercultural }\end{array}$ & $\begin{array}{l}\text { Universidade Federal de } \\
\text { Mato Grosso }\end{array}$ \\
\hline $\begin{array}{l}\text { Vieira (2018) } \\
\text { Dissertação }\end{array}$ & $\begin{array}{l}\text { Escola indígena diferenciada: a experiência Yanomami no } \\
\text { Médio rio Negro }\end{array}$ & $\begin{array}{l}\text { Universidade de São } \\
\text { Paulo }\end{array}$ \\
\hline
\end{tabular}

Fonte: Elaborado pelos autores a partir de informações do Catálogo de Teses e Dissertações da CAPES, 2021

As produções acadêmicas selecionadas compreendem o período de 2013 a 2018, oriundas de Programas de Pós-Graduação em Educação, vinculadas à Universidade de 
São Paulo (3), Universidade Federal do Pará (2), Universidade Federal de Mato Grosso (2), Universidade Estadual de Campinas (2), Universidade Estadual de Mato Grosso (1), Universidade Federal do Amazonas (1), Universidade Federal de Rondônia (1), Universidade Federal de Uberlândia (1), Universidade Federal de São Carlos (1), e Universidade Federal do Tocantins (1). Das 15 pesquisas, 8 perfazem Instituições de Ensino Superior (IES) localizadas na ALB.

\section{O PESQUISAR DA EDUCAÇÃO ESCOLAR INDÍGENA NA ALB}

Para verificar enfoques e contribuições de pesquisas brasileiras que tematizam a educação escolar indígenas na ALB em programas de pós-graduação em educação, no período de 2010 a 2019, fizemos a leitura na íntegra das produções acadêmicas ${ }^{5}$ de Abbonizio (2013), Neto (2013), Abreu (2014), Bastos (2014), Santos (2014), Castro (2015), Rodrigues (2016), Prates (2016), Câncio (2017), Corezomaé (2017), Mendes (2017), Cunha (2018), Feitosa (2018), Paula (2018) e Vieira (2018).

Dos 9 estados que compartilham a ALB, 6 são tematizados nas produções acadêmicas: Acre (1), Amapá (1), Amazonas (4), Mato Grosso (3), Pará (4) e Rondônia (2), conforme sistematização no Quadro 3, no qual também apresentamos o objetivo geral da pesquisa, terra indígena e povo indígena amazônida tematizado.

5 As pesquisas de Abbonizio (2013), Santos (2014), Câncio (2017), Vieira (2018) e Feitosa (2018) não possuem divulgação autorizada no Catálogo de Teses e Dissertações da CAPES, conquanto foram encontradas no repositório da IES as quais estão vinculadas. 
Quadro 3 - Corpus da pesquisa sistematizado por unidade federativa que compartilham a ALB, 2013-2018

\begin{tabular}{|c|c|c|c|c|}
\hline UF & Autor & Objetivo Geral & $\begin{array}{l}\text { Terra Indí- } \\
\text { gena }\end{array}$ & $\begin{array}{c}\text { Povos indíge- } \\
\text { nas }\end{array}$ \\
\hline ACRE & $\begin{array}{l}\text { Castro } \\
(2015)\end{array}$ & $\begin{array}{l}\text { Analisar as propostas e as ações da educação escolar indí- } \\
\text { gena Huni Kuin. }\end{array}$ & $\begin{array}{l}\text { Kaxinawá } \\
\text { Ashaninka } \\
\text { do Rio Breu }\end{array}$ & $\begin{array}{l}\text { Kaxinawá e } \\
\text { Ashaninka }\end{array}$ \\
\hline $\begin{array}{l}\text { AMA- } \\
\text { PÁ }\end{array}$ & $\begin{array}{l}\text { Bastos } \\
(2014)\end{array}$ & $\begin{array}{l}\text { Compreender como as políticas indigenistas voltadas para } \\
\text { a educação e para o ensino no Brasil foram acolhidas, } \\
\text { apropriadas e praticadas nas escolas do Uaçá. }\end{array}$ & Uaça & $\begin{array}{l}\text { Palikur, } \\
\text { Karipuna e } \\
\text { Galibi -Ma- } \\
\text { rworno }\end{array}$ \\
\hline \multirow{4}{*}{$\begin{array}{l}\text { AMA- } \\
\text { ZONAS }\end{array}$} & $\begin{array}{l}\text { Abbonizio } \\
\quad(2013)\end{array}$ & $\begin{array}{l}\text { Definir a educação escolar indígena a partir da relação que } \\
\text { esta estabelece com as aspirações de futuro na comunida- } \\
\text { de indígena. }\end{array}$ & $\begin{array}{l}\text { Alto do Rio } \\
\text { Negro }\end{array}$ & $\begin{array}{l}\text { Kotiria - Wa- } \\
\text { nano }\end{array}$ \\
\hline & Neto (2013 & $\begin{array}{l}\text { Conhecer práticas pedagógicas dos(as) professores(as) } \\
\text { Mura que atuam na } 1^{\mathrm{a}} \text { a } 4^{\mathrm{a}} \text { séries - na Escola Municipal } \\
\text { Indígena Dr. Jacobina da Comunidade de São Félix - e } \\
\text { suas (inter)relações com seu Projeto Político-Pedagógico. }\end{array}$ & Recreio & Mura \\
\hline & Vieira (2018) & $\begin{array}{l}\text { Verificar em quais aspectos a experiência escolar yano- } \\
\text { mami praticada na calha do rio Marauiá, Santa Izabel do } \\
\text { Rio Negro, Amazonas, supera a educação com finalidade } \\
\text { colonialista a qual muitos grupos indígenas foram e são } \\
\text { submetidos. }\end{array}$ & Yanomami & Yanomami \\
\hline & $\begin{array}{l}\text { Cunha } \\
(2018)\end{array}$ & $\begin{array}{l}\text { Investigar, a partir de diversas "letras" produzidas no perí- } \\
\text { odo colonial, os princípios e as motivações dos diferentes } \\
\text { agentes que atuaram nos projetos escolares para povos in- } \\
\text { dígenas do Vale do rio Amazonas. }\end{array}$ & --- & $\begin{array}{l}\text { Povos indíge- } \\
\text { nas do Vale } \\
\text { do rio Ama- } \\
\text { zonas }\end{array}$ \\
\hline \multirow{3}{*}{$\begin{array}{l}\text { MATO } \\
\text { GROSSO }\end{array}$} & Prates (2016) & $\begin{array}{l}\text { Apresentar uma reflexão sobre as práticas docentes no en- } \\
\text { sino de Arte na educação escolar indígena, tendo como } \\
\text { parâmetros as noções de colonialidade e a interculturali- } \\
\text { dade. }\end{array}$ & $\begin{array}{l}\text { Tereza Cris- } \\
\quad \text { tina }\end{array}$ & Bororo \\
\hline & $\begin{array}{l}\text { Corezomaé } \\
\quad(2017)\end{array}$ & $\begin{array}{l}\text { Compreender a partir da perspectiva do povo Balatiponé- } \\
\text {-Umutina os processos educativos entre educandos e edu- } \\
\text { cadores da Escola de Educação Indígena Julá Paré. }\end{array}$ & Umutina & $\begin{array}{l}\text { Balatiponé- } \\
\text {-Umutina }\end{array}$ \\
\hline & Paula (2018) & $\begin{array}{l}\text { Investigar o processo de implantação da instituição escolar } \\
\text { entre os Apyãwa (Tapirapé). }\end{array}$ & $\begin{array}{l}\text { Urubu } \\
\text { Branco e } \\
\text { Tapirapé } \\
\text { Karajá }\end{array}$ & $\begin{array}{l}\text { Apyãwa - } \\
\text { Tapirapé }\end{array}$ \\
\hline \multirow{4}{*}{ PARÁ } & Abreu (2014) & $\begin{array}{l}\text { Analisar as ações desenvolvidas pela SEMED para imple- } \\
\text { mentar a educação escolar indígena diferenciada no muni- } \\
\text { cípio de Santarém. }\end{array}$ & --- & Santarém/PA \\
\hline & $\begin{array}{l}\text { Rodrigues } \\
\text { (2016) }\end{array}$ & $\begin{array}{l}\text { Examinar a educação escolar indígena em atividade na } \\
\text { Terra Indígena Maró, à luz do movimento de reafirmação } \\
\text { étnica dos Borari e Arapium. }\end{array}$ & $\begin{array}{l}\text { Nhamundá/ } \\
\text { Mapuera }\end{array}$ & Wai-wai \\
\hline & $\begin{array}{l}\text { Câncio } \\
(2017)\end{array}$ & $\begin{array}{l}\text { Analisar, com base na teoria decolonial, os sentidos que } \\
\text { assume a aquisição da Língua Portuguesa pelos indígenas } \\
\text { Wai-wai da Aldeia Mapuera, Amazônia brasileira. }\end{array}$ & Maró & $\begin{array}{l}\text { Borari } \\
\mathrm{e} \\
\text { Arapium }\end{array}$ \\
\hline & $\begin{array}{l}\text { Feitosa } \\
(2018)\end{array}$ & $\begin{array}{l}\text { Deslindar o processo de escolarização dos Mẽbêngôkre } \\
\text { Gorotire. }\end{array}$ & Kayapó & $\begin{array}{l}\text { Mẽbêngôkre - } \\
\text { Kayapó }\end{array}$ \\
\hline \multirow{2}{*}{$\begin{array}{l}\text { RON- } \\
\text { DÔNIA }\end{array}$} & $\begin{array}{l}\text { Santos } \\
(2014)\end{array}$ & $\begin{array}{l}\text { Analisar os impactos das políticas públicas de educação } \\
\text { escolar indígena para as comunidades pertencentes ao } \\
\text { Município de Guajará Mirim-RO }\end{array}$ & $\begin{array}{l}\text { Lage e } \\
\text { Rio Negro } \\
\text { Ocaia }\end{array}$ & Wari' \\
\hline & $\begin{array}{l}\text { Mendes } \\
(2017)\end{array}$ & $\begin{array}{l}\text { Analisar práticas político-pedagógicas, relacionadas aos } \\
\text { etnoconhecimentos do povo indígena Paiter Suruí. }\end{array}$ & $\begin{array}{l}\text { Paiterey } \\
\text { Karah }\end{array}$ & Paiter Suruí \\
\hline
\end{tabular}

Fonte: Elaborado pelos autores, a partir das informações do Catálogo de Teses e Dissertações da CAPES, 2021 
A educação escolar indígena, reverberada no corpus desta pesquisa, é tematizada com 17 povos indígenas na ALB, localizados em 15 territórios, vislumbrados na Figura 1: Kaxinawá Ashaninka do Rio Breu, no Acre; Uaça, no Amapá; Alto do Rio Negro, Recreio e Yanomami, no Amazonas; Tereza Cristina, Umutina, Urubu Branco e Tapirapé Karajá, no Mato Grosso; Nhamundá - Mapuera, Maró e Kayapó, no Pará; e Lage, Rio Negro Ocaia e Paiterey Karah, em Rondônia.

Figura 1 -Terras Indígenas na ALB tematizadas no corpus da pesquisa, 2013-2018

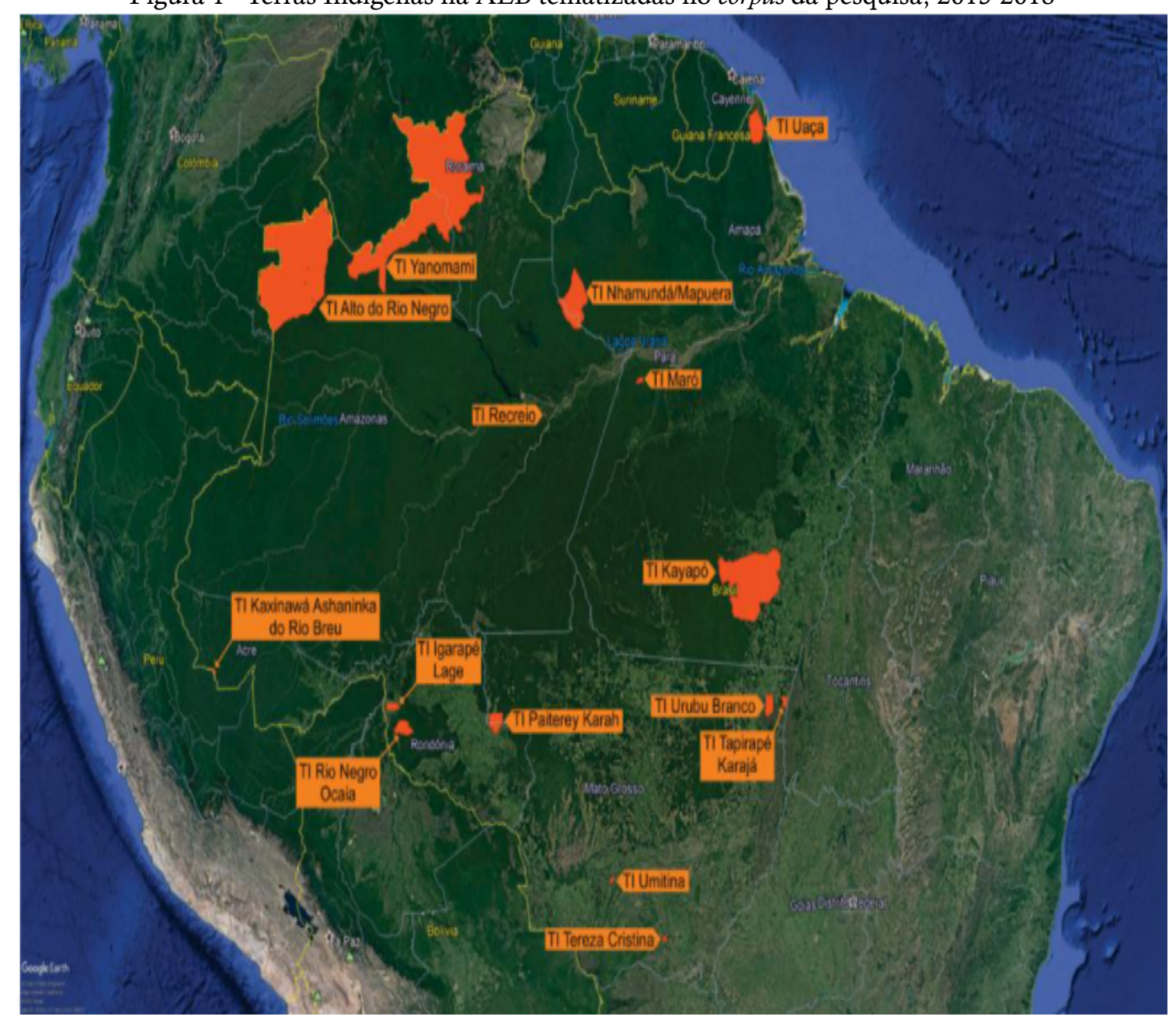

Fonte: Adaptado da Fundação Nacional do Índio, 2021.

Tematizando a educação escolar no território indígena Kaxinawá e Ashaninka do Rio Breu, localizada no estado do Acre, região de fronteira entre Brasil e Peru, Castro (2015) analisa, à luz da etnografia, as propostas e ações da educação escolar indígena Huni Kuin ${ }^{6}$ nas aldeias Vida Nova e Jacobina, respectivamente, nas escolas estaduais Rainha da Floresta e Jacobina. A partir dos depoimentos orais de 12 indígenas Huni Kuin, professores e lideranças, e 6 não indígenas, representantes da Secretaria Estadual de Educação do Acre e Conselho Indigenista Missionário (CIMI), bem como observações realizadas em sala de aula, conclui que as escolas indígenas "se constitui ao mesmo tempo diante da perspectiva das instituições da sociedade nawá e da perspectiva da socie-

6 Os Huni Kuin, povo amazônico de língua Pano, são mais conhecidos por Kaxinawá. Tal denominação é dada por outros grupos indígenas vizinhos, em que Kaxi significa "morcego" ou "canibal", mas pode significar também "gente com hábito de andar à noite". Nawá, por sua vez, faz referência ao estrangeiro, ao outro (CALAVIA SAEZ, 2000 p. 40 apud CASTRO, 2015, p.19). 
dade huni kuin, em que um dos fundamentos essenciais é a incorporação do projeto de interculturalidade para a qual é projetada" (CASTRO, 2015, p. 128).

A autora ainda explica que os Huni Kuin do Breu desenvolvem maneiras particulares nas articulações "com e para as suas escolas", reinventando-as no "intuito de fazer conhecimento, entretanto, estão sempre à mercê do sistema burocrático, sem compreender a funcionalidade". Situação que se agrava mais ainda ao perceber que "nem os próprios agentes dos órgãos institucionais compreendem a complexidade do sistema em que estão inseridos" (CASTRO, 2015, p. 128).

Bastos (2014) nos conduz ao município de Oiapoque-AP, localizado na fronteira entre Amapá e Guiana Francesa. Temporaliza os anos de 1964 e 1985, momento em que o governo militar reformulou tanto as políticas indigenistas como a legislação educacional, implementando um modelo de educação escolar para indígenas Palikur ${ }^{7}$, Karipuna ${ }^{8}$ e Galibi-Maworno9. À vista disso, propôs compreender como as políticas indigenistas voltadas para a educação e para o ensino no Brasil foram acolhidas, apropriadas e praticadas nas escolas do Uaçá e de que forma foi se estabelecendo uma cultura de educação escolar associada ao significado de educação própria dos indígenas.

Por meio da memória documental, a autora depreende que a educação escolar "difundida nas escolas indígenas fabricou marcas, regras e costumes, mesclando-se a educação própria da cultura indígena, demarcando um processo de apropriação e ressignificação da escola nas aldeias". A cultura de educação escolar em territórios indígenas "foi marcada por dispositivos externos à cultura e à identidade dos indígenas do Uaçá, envolvendo uma rede ampla de relações estabelecidas e redimensionadas por práticas e normas construídas na escola", no escopo de "fixar os indígenas na fronteira brasileira, atendendo aos propósitos de segurança nacional" (BASTOS, 2014, p. 151).

No vislumbre substancial de direcionar para outra possibilidade de pensar, no presente, a educação e a escola em territórios indígenas como uma prática histórica e culturalmente produzida, e estabelecendo compreensão sob outra perspectiva, Bastos (2014, p. 151) reverbera que a escola "atuou como um espaço de reinvenção da educação num lugar de cultura diferenciada".

Comparecendo na diversidade dos povos indígenas no estado do Amazonas, Abbonizio (2013), Neto (2013), Vieira (2018) e Cunha (2018) propõem-se a contribuírem com o debate mais amplo acerca da educação escolar indígena com grupos indígenas

\footnotetext{
7 Os Paikwené, mais conhecidos como Palikur, são indígenas falantes da língua arawak. Os Palikur estão divididos entre os dois lados da fronteira Brasil/ Guiana Francesa. Em território brasileiro, estão localizados no extremo norte do Estado do Amapá, no perímetro do município de Oiapoque, na região da bacia do Uaçá, um tributário do baixo rio Oiapoque (POVOS, 2021).

80 termo Karipuna é usado como autodenominação por essa população e indica uma identidade de indios misturados ou civilizados, que é tanto atribuída como assumida pelas famílias Karipuna. Falantes da língua português e patois, os Karipuna fazem parte do complexo de povos indígenas da região do baixo rio Oiapoquea (POVOS, 2021).

9 Galibi-Marworno é uma autodesignação bastante recente, que se cristalizou principalmente na última década. substituindo o termo Galibi do Uaçá ou, simplesmente, do Uaçá, Uaçauara ou mun Uaçá. Os que assim se autodenominam constituem um povo oriundo de populações etnicamente diversas: Aruã, Maraon, Karipuna (falantes da língua geral derivada da tupi), Galibi (falantes da língua geral derivada da galibi) e até não-índios. A maior parte da população Galibi-Marworno vive na TI Uaçá, no norte do Estado do Amapá (POVOS, 2021).
} 
Kotiria-Wanano ${ }^{10}$, Mura ${ }^{11}$ e Yanomami ${ }^{12}$, bem como evidenciar o andarilhar histórico no Vale do rio Amazonas.

Intentando definir a educação escolar indígena, a partir da relação que esta estabelece com as aspirações de futuro na comunidade indígena, Abbonizio (2013) realizou estudo de caso na Escola Indígena Khumuno Wu'u, localizada no Território Indígena Kotiria-Wanano, aldeia Caruru Cachoeira, município de São Gabriel da Cachoeira-AM, região de fronteira entre o Brasil e Colômbia.

Andarilhando por discussões acerca da educação escolar convencional; inovação, reforma e mudança educacional; escolarização e projetos de futuro; e, os Kotiria e sua escola, a autora certificou a hipótese de pesquisa de que experiências recentes de escolarização indígena vêm buscando compatibilizar objetivos escolares com objetivos comunitários, uma vez que os Kotiria "ao refletirem sobre o que querem da sua escola [...] elaboram e executam seus planos para o contexto atual e para novas gerações", fazendo com que a escola torne-se "espaço principal de reunião comunitária, debate e intervenção sobre as condições de vidas atuais e futuras" (ABBONIZIO, 2013, p. 179).

Neto (2013), pesquisador indígena Mura, desafiado a responder a inquire: de que modo os(as) professores(as) Mura da Escola Municipal Indígena Dr. Jacobina implementam o Projeto Político-Pedagógico Mura ao desenvolverem suas práticas pedagógicas com classes de $1^{\mathrm{a}}$ a $4^{\mathrm{a}}$ séries?, propôs conhecer, por meio de estudo de campo, práticas pedagógicas dos(as) professores(as) Mura que atuam na $1^{\mathrm{a}}$ a $4^{\mathrm{a}}$ séries, na Escola Municipal Indígena Dr. Jacobina da Comunidade de São Félix-AM, e suas (inter)relações com seu Projeto Político-Pedagógico.

Com base nos conhecimentos da sua educação Mura, e substanciado metodologicamente na tríade entrevistas, análise documental e observação, respectivamente, com 4 professores Mura, Planejamento de Aula e Projeto Político Pedagógico (PPP) Mura, e cotidiano da escola e salas de aulas, conclui que o "PPP-Mura foi elaborado como modelo de projeto para atender os anseios do povo Mura", ao vislumbrar que "as aulas ministradas pelos(as) professores(as) investigados(as) na Escola Municipal Indígena Dr. Jacobina têm conseguido atender as propostas descritas no documento", à vista disso "constituindo valores próprios desse povo, pois percebem o espaço escolar como palco de valorização de sua cultura e fortalecimento da identidade" (NETO, 2013, p. 217).

Vieira (2018) apresenta o cenário da educação escolar Yanomami, especificamente a promovida pela organização não governamental Serviço e Cooperação com o Povo Yanomami (Secoya), presente na região desde a década de 1990. Por meio de pesquisa de campo, verifica em quais aspectos a experiência escolar Yanomami praticada na calha

\footnotetext{
10 Os Kotira, localizados no rio Uaupés, fronteira entre Brasil e Colômbia, são um dos 12 povos da família linguística Tukano Oriental que vivem em território brasileiro, e se autodeterminam Wanano (ABBONIZIO, 2013, p. 17-18).

11 Os Mura ocupam vastas áreas no complexo hídrico dos rios Madeira, Amazonas e Purus. Atualmente, os Mura, falantes de Português, assim como outros povos amazônicos que perderam suas línguas maternas, reafirmam o Nheenhatu como uma língua indígena. No presente, vêm realizando esforços de valorização e resgate linguístico e cultural das diversas "gírias" da língua Mura (POVOS, 2021).

12 Os Yanomami estão situados em ambos os lados da fronteira Brasil-Venezuela na região do interflúvio Orinoco - Amazonas, formam uma sociedade de caçadores-agricultores da floresta tropical do Norte da Amazônia. O etnônimo Yanomami foi produzido pelos antropólogos a partir da palavra yanõmami que, na expressão yanõmami thëpë, significa seres humanos (POVOS, 2021).
} 
do rio Marauiá, Santa Izabel do Rio Negro-AM, supera a educação com finalidade colonialista a qual muitos grupos indígenas foram e são submetidos.

Ao vislumbrar que as escolas não possuem nenhum vínculo com ordem religiosa $\mathrm{e}$ que o desejo de frequentar parte do estudante, assim como os PPP são elaborados por professores e lideranças Yanomami; que as práticas pedagógicas procedem na língua materna, realizadas exclusivamente por professores Yanomami escolhidos pela comunidade; que os conhecimentos indígenas e não indígenas perfazem a matriz curricular, visando a instrumentar estudantes para os desafios do pós-contato e, ao mesmo tempo, para valorização da cultura tradicional; e que há calendário escolar diferenciado que inclui atividades das comunidades como festejos, acampamentos e caçadas coletivas, o autor conclui que a "escola diferenciada Yanomami supera aspectos da educação colonialista [...], contribuindo para a autonomia e autodeterminação do povo ao qual devem servir" (VIEIRA, 2018, p. 149) .

Cunha (2018), intencionando em compreender a história da educação escolar indígena no período colonial do Vale do rio Amazonas, propôs, à luz de pesquisa documental, uma investigação a partir de diversas letras produzidas no período colonial, os princípios e as motivações dos diferentes agentes que atuaram nos projetos escolares para povos indígenas do Vale do rio Amazonas.

O autor constata, ao andarilhar pela memória da educação escolar indígena no período jesuíta e Amazônia pombalina, que a escola "projetada para ser o instrumento que iria espargir e dispersar as luzes da civilidade, não conseguiu superar às intempéries culturais e as adversidades sociais com as quais teve que se confrontar". Reverberando ainda que na "condição de "luz" para as mentes e corpos que necessitavam de civilidade, a escola foi "apagada", tanto pelas penumbras da selva quanto pelas sombras da metrópole", pela ação do "falso discurso do prestígio e prioridade da educação" (CUNHA, 2018, p. 193).

Tematizando acerca dos saberes culturais e locais Bororo ${ }^{13}$, processos educativos Balatiponé-Umutina ${ }^{14}$ e implantação da instituição escolar no território Apyãwa-Tapirapé $^{15}$, Prates (2016), Corezomaé (2017) e Paula (2018) tematizam a educação escolar indígena no estado do Mato Grosso.

Apresentando uma reflexão a respeito das práticas docentes no ensino de Arte na educação escolar indígena, tendo como parâmetros as noções de colonialidade e interculturalidade, Prates (2016), por meio de pesquisa de campo, discute o ensino de Arte em sua dimensão universal e os saberes culturais e locais produzidos na Escola Estadual

\footnotetext{
13 O termo Bororo significa na língua nativa pátio da aldeia. Não por acaso, a tradicional disposição circular das casas faz do pátio o centro da aldeia e espalho ritual desse povo, caracterizado por uma complexa organização social e pela riqueza de sua vida cerimonial. Boe Wadáru é o termo usado pelos Bororo para designar sua língua original. Num território descontínuo e descaracterizado, os Bororo detêm seis Terras Indígenas (POVOS, 2021).

14 Os Umutina se autodeterminam de Balotiponé, cujo significado é gente nova. Localizados no estado do Mato Grosso, os Umutina não falam mais a língua indígena, classificada como pertencente ao tronco linguístico Macro-Jê, da família Bororo, devido a violência de contato com os não indígenas (POVOS, 2021).

15 Os Tapirapé, se autodeterminam de Apyãwa, constituem um povo Tupi-Guarani habitante da região da floresta tropical, com flora e fauna tipicamente amazônicas (POVOS, 2021).
} 
Indígena Korogedo Paru, localizada na aldeia Córrego Grande, povo Bororo, TI Teresa Cristina, munícipio de Santo Antônio de Leverger-MT.

Ao entrelaçar arte e educação na perspectiva cultural, política e social, e arte na educação escolar indígena, a autora diz que o ensino de Arte é uma "ferramenta para a constituição de identidade dos estudantes bororo com elementos culturais autóctones, acrescidos dos conhecimentos produzidos pelas demais sociedades". Contudo, ao aproximar o currículo da escola indígena e a práxis docente, ressalta com veemência haver "necessidade de amainar a distância entre o currículo formal da escola e a práxis docente efetiva de modo a viabilizar um currículo específico em Arte Universal" (PRATES, 2016, p. 110).

Interpelando quanto aos processos educativos próprios da Escola Estadual Indígena Julá Paré, Corezomaé (2017), pesquisador indígena Balatiponé-Umutina, propôs compreender, à luz da história oral e a partir da perspectiva do povo Balatiponé-Umutina, os processos educativos entre educandos e educadores da Escola Estadual Indígena Julá Paré, aldeia Umutina, localizada no Terra indígena Umutina, Barra do Bugres - MT.

Analisando as narrativas orais, reverberadas por 10 indígenas Balatiponé-Umutina: pais, estudantes e professores da escola, desenvolve a análise de pesquisa em duas categorias: "Epistemologia Balatiponé-Umutina; e "As lutas para conquista de uma Educação Escolar Diferenciada" (COREZOMAÉ, 2017, p. 6).

À vista dessas especificações, o autor compreende que a cultura Balatiponé-Umutina perfaz o processo de ensino e aprendizagem na escola, sobretudo por vislumbrar o "compromisso de ensinar as diversas manifestações culturais do povo Balatiponé-Umutina [...] as curas, as danças e a língua do povo Balatiponé-Umutina, [...] aulas de campo em que os/as anciões/ãs participam e rememoraram histórias". A afirmação da cultura Balatiponé-Umutina no espaço escolar resulta de "constante processo de luta", especialmente pelo rompimento "com a lógica inicial para qual a Escola foi criada" (COREZOMAÉ, 2017, p. 70).

Fazendo uma reflexão acerca da realidade do povo indígena Apyãwa-Tapirapé quanto à ruptura com os modelos seculares de educação escolar indígena, Paula (2018), pesquisador indígena Apyãwa, investiga o processo de implantação da instituição escolar entre os Apyãwa-Tapirapé, em duas Terras indígenas: Tapirapé-Karajá e Urubu Branco, respectivamente nos municípios de Santa Terezinha-MT, Confresa-MT, Porto Alegre do Norte-MT e Santa Terezinha-MT.

Ao entrelaçar, à luz da pesquisa de campo, as narrativas orais de 5 Apyãwa-Tapirapé e 2 não indígenas, narrativas imagéticas - fotografias e documentos institucionais - , o autor discorre acerca da educação Apyãwa, implantação da escola e os desafios enfrentados pelas escolas Apyãwa ao longo do processo de escolarização em seu território, concluindo que a "escola implementada entre os Apyãwa na década de setenta instaurou rupturas com os modelos colonialistas vigentes, a começar pelo pedido explicitado pelo 
povo que se encontrava empenhado na luta pela demarcação de um território" (PAULA, 2018, p. 93).

Considerando-os "sujeitos de seus próprios processos de aprendizagem" e estabelecendo "relações simétricas entre professores e estudantes no espaço escolar", o autor segue mencionando que o respeito e a valorização da língua materna e da cultura do povo Apyãwa seguem os "princípios filosóficos e metodológicos inspirados em Paulo Freire", com vista na exemplificação a partir da construção coletiva e respeito à ortografia da língua originária (PAULA, 2018, p. 93).

Paula (2018, p. 93) ainda explica que o "respeito à língua e à cultura também são destacados como marcas importantes da Escola", contudo revela que o "desejo de dominar a língua portuguesa" perfaz nitidamente o tracejo da escola para "enfrentar com maior segurança os desafios colocados pela situação pós-contato".

Andarilhando na educação escolar indígena na Amazônia paraense, Abreu (2014), Rodrigues (2016), Câncio (2017) e Feitosa (2018), tratam, nesta ordem, das políticas públicas da educação escolar indígena no município de Santarém-PA ${ }^{16}$; processos de reafirmação étnica dos Borari ${ }^{17}$ e Arapium; aquisição da língua portuguesa por indígenas Wai-wai ${ }^{18}$; e processo de escolarização de Mẽbêngôkre-Kayapó ${ }^{19}$.

Abreu (2014), a partir do indicativo do problema de pesquisa: de que forma o direito à educação diferenciada, garantida nos marcos legais aos povos indígenas, vem sendo implementada no município de Santarém-PA?, analisou, substanciado na pesquisa documental de temporalidade de 2006 a 2012, as ações desenvolvidas pela Secretaria Municipal de Educação para implementar a educação escolar indígena diferenciada no município de Santarém-PA.

Tratando do direito à igualdade e a diferença em educação, os direitos dos povos indígenas a uma educação diferenciada, bem como a educação escolar indígena no município de Santarém-PA, o autor conclui que "[...] mesmo que a partir de 1988 a bem jurídica educação indígena diferenciada tenha sido elevada à categoria de direito, no caso de Santarém, a SEMED não foi capaz de dar eficácia a essa conquista normativa", sobretudo ao evidenciar que "todas suas ações voltadas à promoção do direito foram realizadas sob reivindicações do movimento indígena”, ao entenderem que a escola seria necessária para "afirmação de suas identidades, já que a identificação de escolas na categoria indígena tornava o ente estatal reconhecedor da existência de grupos étnicos em seu território" (ABREU, 2014, p. 130).

\footnotetext{
16 A educação escolar indígena no município de Santarém-PA envolve 13 etnias: Tupaiu, Borari, Arapium, Tupinambá, Tapuia, Munduruku, Munduruku Cara Preta, Maitapu, Apiaka, Jaraki, Arara Vermelha, Tapajó e Kumaruara (ABREU, 2014).

17 Os Borari e os Arapium são um povo indígena que habitam as margens dos rios Tapajós e Maró-Arapiuns no oeste do estado do Pará, e atualmente são falantes apenas da língua portuguesa, guardando na memória dos mais velhos, o tempo da gíria, forma como denominam o Nheengatu (SILVA, 2011 apud RODRIGUES, 2016).

18 Os Waiwai estão localizados nos rios Anauá e Jatapuzinho em Roraima, rios Jatapu e Nhamundá no Amazonas, e rio Mapuera no Pará. A língua Waiwai, que pertence à família linguística Karib, constitui o idioma principal utilizado pelos habitantes das comunidades Waiwai (POVOS, 2021).

19 Os M $\square$ bêngôkre, povo do buraco d'água, mais conhecidos como Kayapó, são indígenas falantes do tronco linguístico Macro-Jê da família Jê. Habitam territórios ao sul do estado do Pará e ao norte do estado do Mato Grosso, fazendo parte da Amazônia Legal Brasileira (FEITOSA, 2018).
} 
Na Terra Indígena Maró, Rodrigues (2016) realizou uma pesquisa de campo para examinar a educação escolar indígena em atividade, à luz do movimento de reafirmação étnica dos Borari e Arapium, acompanhando atividades escolares, no que tange ao funcionamento das escolas e processo de ensino escolar, e auscultando lideranças indígenas, estudantes e funcionários da escola.

Ao registrar a implantação e atividade da educação escolar nas comunidades indígenas do oeste do Pará, o autor diz que a escola tem se configurado como instrumento importante para o fortalecimento das lutas indígenas, ao oferecer, "por exemplo, espaços para articulações em torno das demandas dos indígenas e instrumento de transmissão e valorização das características étnicas diferenciadoras". À vista disso, conclui que a "educação escolar atualmente oferecida aos indígenas da Terra Indígena Maró contribui para o fortalecimento do processo de reafirmação étnica dos Borari e dos Arapium", por meio, principalmente da práxis de atividades pedagógicas realizadas nas "disciplinas de Notório Saber e Língua Indígena Nheengatu” (RODRIGUES, 2016, p. 176).

Analisando, com base na teoria decolonial, os sentidos que assume a aquisição da Língua Portuguesa pelos indígenas Wai-wai da Aldeia Mapuera, Câncio (2017, p. 254), por meio de estudo de caso do tipo etnográfico, constatou que "a aquisição da Língua Portuguesa, historicamente reivindicada pelos indígenas Wai-wai da Aldeia Mapuera, embora ocorra de forma a tentar negar suas culturas [...], produziu (e ainda produz) práticas de resistência e enfrentamentos".

O autor sustenta a constatação pelo vislumbre de que "[...] a aquisição da Língua Portuguesa, inicialmente, só foi possível pelo enfrentamento dos missionários que tentaram embargar esse processo na aldeia", e também pelo fato de que, atualmente, para além da escola e da aldeia, a aquisição da língua portuguesa torna-se necessária "nos espaços de circulação com os não indígenas [...]," ou seja, "comunicação mobilizads pelas necessidades". Em outras palavras, ainda explica o autor, esse é o "modo de existir que permite que eles se desconectem, no sentido particular de não comungarem com pensamentos que lhes desfavoreçam, nos modos de operação de suas ideologias" (CÂNCIO, 2017, p. 254).

Adentrando o território Mẽbêngôkre-Kayapó para deslindar o processo de escolarização dos Gorotire, comunidade indígena localizada no município de Cumaru do Norte-PA, Feitosa (2018), inspirada na História Oral, reverbera, a partir das narrativas orais de 9 Mẽbêngôkre-Kayapó e 5 não indígenas, da análise documental constituída no âmbito municipal e estadual, e da análise de imagem de 8 desenhos criados por crianças Mẽbêngôkre-Kayapó em processo de escolarização, que o adentrar da escola na aldeia Gorotire é recente.

A escolarização dos Mẽbêngôkre-Kayapó Gorotire, segundo a autora, foi principiada em 1973 e andarilhada por ressignificações para "concebê-la no âmago da autonomia e reafirmação de sua identidade". O processo de escolarização foi gerido por vários agentes sociais e institucionais: "Missão Cristã Evangélica do Brasil, Summer Institute 
of Linguistics, Fundação Nacional do Índio, garimpeiros, madeireiros e os próprios Gorotire", e atualmente pela "Secretaria Municipal de Educação e Secretaria de Estado de Educação do Pará" (FEITOSA, 2018, p.185).

A autora ainda menciona que a escola é representada "como local de apropriamento da cultura dos Kuben e dinamização para o ingresso em suas atividades laborais, assim como um ambiente de fomento a sua cultura". Contudo, enfatiza que as crianças em processo de escolarização percebem maneiras distintas de aprendizagens comunicadas em seu território procedentes da educação Mẽbêngôkre e escolar (FEITOSA, 2018, p.188).

Tratando da educação escolar indígena no estado de Rondônia, as pesquisas de Santos (2014) e Mendes (2017) têm assento, nesta ordem, na análise de políticas públicas educacionais em territórios indígenas no município de Guajará-Mirim-RO, povo Wari ${ }^{20}$, e práticas político-pedagógicas do povo indígena Paiter Suruí ${ }^{21}$.

Santos (2014) analisa e descreve, por meio de estudo etnográfico em educação, os impactos das políticas públicas de educação escolar indígena para as comunidades pertencentes ao Município de Guajará Mirim-RO, povo Wari', nas aldeias Lage Velho, Linha 10 e Rio Negro Ocaia.

Ao entoar o histórico da educação escolar indígena, o mundo social histórico do povo Wari' e a luta pela educação escolar, a autora menciona que, desde a implementação de políticas educacionais nas comunidades indígenas do povo Wari', floresceram várias reivindicações: prédio adequado; material didático na língua materna; alimentação escolar; e principalmente a autonomia da escola diferenciada em seu território. Conquanto, sublinha que essas reivindicações são "apenas alguns passos que se dão em direção a uma caminhada que demanda uma compreensão em distintas dimensões, para que seja construída uma escola indígena dentro de uma perspectiva que considere a autonomia e a idiossincrasia Wari' " (SANTOS, 2014, p. 95).

Andarilhando na historicidade dos Paiter Suruí, sua constituição social, aplicabilidade dos direitos e alguns aspectos da educação familiar e escolar de estudantes do ensino fundamental e médio das escolas indígenas ofertadas a esse grupo indígena, Mendes (2017) analisa, por meio de observação participante, as práticas políticas-pedagógicas relacionadas aos etnoconhecimentos do Paiter Suruí.

À vista das práticas políticas-pedagógicas observadas e analisadas, a autora evidencia que os "Paiter Suruí são detentores de uma cultura riquíssima", e a práxis da interculturalidade é, sem dúvida, um "processo mediatizador de etnoconhecimentos". Diante disso, conclui haver necessidade de produção de materiais didáticos bilíngue ou multilíngue substanciados nos etnoconhecimentos Paiter Suruí, para que professores, indígenas

20 Os Wari' são muitas vezes designados como Pakaa Nova, por terem sido avistados pela primeira vez no rio homônimo, afluente da margem direita do Mamoré, Rondônia. Mas é como Wari', palavra na sua língua que significa gente, nós, que gostam de ser chamados, e é dessa forma que são conhecidos pelos não indígenas que mantêm com eles um convívio mais estreito (POVOS, 2021).

21 Os Suruí de Rondônia se autodenominam Paiter, que significa gente de verdade, nós mesmos. Falam uma língua do grupo Tupi e da família linguística Mondé. A Terra Indígena Sete de Setembro, onde vivem os Paiter, está localizada numa região de fronteira entre Rondônia e Mato Grosso (POVOS, 2021). 
e não indígenas possam promover diálogos interculturais, entrelaçando os etnoconhecimentos produzidos em seus territórios com os conhecimentos não indígenas (MENDES, 2017, p. 130-131).

\section{TECENDO CONSIDERAÇÕES AMAZÔNICAS}

A análise das produções acadêmicas, desenvolvidas nos programas de pós-graduação em educação que tematizam a educação escolar indígena na ALB, nos permitiu vislumbrar a diversidade étnica, cultural, populacional e territorial dos povos indígenas que a compartilham, assim como a compleição de pesquisadores indígenas amazônidas Mura, Balatiponé-Umutina e Apyãwa.

As pesquisas possuem vários enfoques acerca da educação escolar indígena na ALB: propostas e ações, práticas pedagógicas de professores indígenas, processos educativos, saberes culturais e locais, projeto político pedagógico, processo de escolarização, aquisição da língua portuguesa, aspirações do futuro de comunidade indígena, políticas indigenistas, inter-relação com a educação indígena, ressignificação do ambiente escolar colonialista, princípios e motivações de diferentes agentes que atuaram nos projetos escolares, e políticas públicas no âmbito municipal.

Essas focagens nos permitem entender que a escola em territórios indígenas na ALB fabricou marcas, regras e costumes partíveis na cultura indígena amazônica para atender os propósitos da cultura não indígena. Conquanto, as experiências recentes de escolarização empenham-se em ofertar, por meio de ressignificações impulsionadas pelos povos indígenas, um ambiente escolar que pratique objetivos escolares e comunitários em seus territórios.

Para se pensar e praticar uma educação escolar diferenciada em territórios indígenas na ALB, os pesquisadores reverberam a necessidade de se construir uma escola comunitária, substanciada na ausculta do que querem da sua escola, na autonomia do gerenciamento escolar, no exercício da prática docente, e sobretudo no entrelaçamento de processos educativos interculturais para sobrelevação dos desafios pós contato.

\section{REFERÊNCIAS}

ABBONIZIO, Aline Cristina de Oliveira. Educação escolar indígena como inovação educacional: a escola e as aspirações de futuro das comunidades. 2013. $193 \mathrm{f}$. Doutorado em Educação Instituição de Ensino: Universidade de São Paulo, São Paulo, 2013. Disponível em:https://www.teses.usp.br/teses/disponiveis/48/48134/tde-16122013153433/pt-br.php. Acesso em: 03 jan. 2021.

ABREU, Joniel Vieira de. A implementação do direito à educação escolar indígena no município de Santarém no período de 2006 a 2012. 2014. 151 f. Dissertação (Mestrado em Educação) - Universidade Federal do Pará, 2014. Disponível em: https://sucupira.capes.gov.br

/sucupira/public/consultas/coleta/trabalhoConclusao/viewTrabalhoConclusao.jsf?popup=true \&id_trabalho=453687. Acesso em: 03 jan. 2021.

ARAGÓN, Luis Eduardo. A dimensão internacional da Amazônia: um aporte para sua interpretação. Revista Nera, ano 21, n. 42, p.15-33, dossiê, 2018. Disponível em: https://rev

ista.fct.unesp.br/index.php/nera/issue/view/28\%20de\%20mar.\%202018. Acesso em: 13 jan. 2021.

BASTOS, Cecilia Maria Chaves Brito. Educação escolar indígena na região do Uaçá no município de Oiapoque- 
AP (1964-1985). 2014. 165 f. Tese (Doutorado em Educação) - Universidade Federal de Uberlândia, Uberlândia, 2014. Disponível em: https://sucupira.cape

s.gov.br/sucupira/public/consultas/coleta/trabalhoConclusao/viewTrabalhoConclusao.jsf?popup=true\&id_ trabalho=1422154. Acesso em: 03 jan. 2021.

CANCIO, Raimundo Nonato de Padua. Para além da aldeia e da escola: um estudo decolonial de aquisição da língua portuguesa pelos indígenas Wai-Wai da aldeia Mapuera, Amazônia brasileira. 2017. 275 f. Tese (Doutorado em Educação) - Universidade Federal do Pará, Belém, 2017. Disponível em: https://sucupira.capes.gov.br/ sucupira/public/consultas/coleta/trabalhoco

nclusao/viewTrabalhoConclusao.jsf?popup=true\&id_trabalho=5061877. Acesso em: 03 jan. 2021.

CASTRO, Maria Zenaide Gomes de. Tecendo novos olhares para a educação escolar indígena: a escola diferenciada Huni Kuin na região do Breu e seus atores. 2015. 150 f. Dissertação (Mestrado em Educação) - Universidade Estadual de Campinas, Campinas, 2015. Disponível em: https://sucupira.capes.gov.br/sucupira/public/consultas/ coleta/trabalhoConcl

usao/viewTrabalhoConclusao.jsf?popup=true\&id_trabalho=2914544.Acesso em: 03 jan. 2021.

COREZOMAE, Lennon Ferreira. Educação escolar do povo indígena Balatiponé-Umutina: compreendendo processos educativos da escola Julá Paré. 2017. 140 f. Dissertação (Mestrado em Educação) - Universidade Federal de São Carlos, São Carlos, 2017. Disponível em: https://repositorio.ufscar.br/handle/ufscar/9306?show=full. Acesso em: 03 jan. 2021.

CUNHA, Jonas Araujo da. Luzes apagadas: a educação escolar indígena na Amazônia colonial. 2018. 218 f. Tese (Doutorado em Educação) - Universidade de São Paulo, São Paulo, 2018. Disponível em: https://teses.usp.br/ teses/disponiveis/48/48134/tde-14122018-093140/publico/JONAS_ARAUJO_DA_CUNHA_rev.pdf. Acesso em: 03 jan. 2021.

FEITOSA, Leni Barbosa. Da flecha à caneta: escolarização indígena $\mathrm{M} \square$ bêngôkre Gorotire. 2018. $242 \mathrm{f}$. Dissertação (Mestrado em Educação) - Universidade Federal do Tocantins, Palmas, 2018. Disponível em: https:// docs.uft.edu.br/share/s/juzxu1ev Qsy6Noy3qcdMTg. Acesso em: 03 jan. 2021.

FUNAI - FUNDAÇÃO NACIONAL DO INDÍO. Povos indígenas isolados e de recém contato. Site, 2021. Disponível em: http://www.funai.gov.br/index.php/nossas-acoes/povos-indigenas-isolados-e-de-recente-contato. Acesso em: 10 jan. 2021.

GRUPIONI, Luís Donisete Benzi. A educação indígena na academia: inventário comentado de dissertações e teses sobre educação escolar indígena no Brasil (1978-2002). Revista em Aberto, Brasília, v.20, n.76, p.197-238, fev. 2003. Disponível em: http://rbep.inep.gov.br/index.php/emaberto/article/view. Acesso em: 10 jan. 2021.

HECK, Egon. LOEBENS, Francisco. CARVALHO, Priscila D. Amazônia Indígena: conquistas e desafios. Estudos Avançados. 2005, vol.19, no.53, p.237-255. Disponível em: https://www.scielo.br/pdf/ea/v19n53/24091.pdf. Acesso em: 10 jan. 2021.

IBGE - INSTITUTO BRASILEIRO DE GEOGRAFIA E ESTATÍSTICA. Amazônia Legal. Site, 2021. Disponível em: htpps://www,ibge.gov.br/geociências/cartas-e-mapas/mapas-regionais/15819-amazonia-legal.html?=\&t=oque-e. Acesso em: 12 jan. 2021.

MELLO, Alex Fiúza de. Apresentação. In: ARAGÓN, Luis Eduardo (Org.). Amazônia: conhecer para desenvolver e conservar, cinco temas para um debate. São Paulo: Hucitec, 2013.

MENDES, Matilde. Educação escolar indígena Paiter Suruí e sua relação com os etnoconhecimentos. 2017. 142 f. Dissertação (Mestrado em Educação) - Universidade do Estado do Mato Grosso, Cáceres, 2017. Disponível em: https://sucupira.capes.gov.br/sucupi

$\mathrm{ra} /$ public/consultas/coleta/trabalhoConclusao/viewTrabalhoConclusao.jsf?popup=true\&id_trabalho=5941613. Acesso em: 03 jan. 2021.

MINISTÉRIO DA EDUCAÇÃO. Novo desenho garante melhorias à Plataforma Sucupira da Capes. Site, 2021. Disponível em: http://portal.mec.gov.br/ultimas-noticias/225-sistemas-1375504326/48451-novo-desenhogarante-melhorias-a-plataforma-da-capes. Acesso em: 05 jan. 2021.

NETO, Jaspe Valle. Educação escolar indígena Mura: por entre práticas docentes e o projeto político-pedagógico. 
2013. 167 f. Dissertação (Mestrado em Educação) - Universidade Federal do Amazonas, Manaus, 2013. Disponível em: https://sucupira.capes.gov.br/sucupira/public/co msultas/coleta/trabalhoConclusao/viewTrabalhoConclusao.jsf?popup=true\&id_trabalho=1199960. Acesso em: 03 jan. 2021.

PAULA, Andre Wanpura de. Escola Apyãwa: da vivência e convivência da educação indígena à educação escolar intercultural. 2018. 109 f. Dissertação (Mestrado em Educação) - Universidade Federal de Mato Grosso, Cuiabá, 2018. Disponível em: https://sucupira.capes.

gov.br/sucupira/public/consultas/coleta/trabalhoConclusao/viewTrabalhoConclusao.jsf?popup=true\&id_ trabalho=6311582. Acesso em: 03 jan. 2021.

POVOS INDÍGENAS NO BRASIL. Quem são? Site 2021. Disponível em: https://pid.socioambiental.org/pt/ Quem_s\%C3\%A3o. Acesso em: 8 jan. 2021.

PRATES, Elen Luci. O ensino de arte na escola indígena Bororo Korogedo Paru da aldeia Córrego Grande MT. 2016. 116 f. Dissertação (Mestrado em Educação) - Universidade Federal de Mato Grosso, Cuiabá, 2016. Disponível em: https://sucupira.capes.gov.br/sucupi

$\mathrm{ra} /$ public/consultas/coleta/trabalhoConclusao/viewTrabalhoConclusao.jsf?popup=true\&id_trabalho=3653260. Acesso em: 03 jan. 2021.

RODRIGUES, Gilberto Cesar Lopes. Surara Borari, Surara Arapium: a educação escolar no processo de reafirmação étnica dos Borari e Arapium da terra indígena Maró. 2016. 216 f. Tese (Doutorado em Educação) - Universidade Estadual de Campinas, Campinas, 2016. Disponível em: https://sucupira.capes.gov.br/sucupira/ public/consultas/coleta/trabalhoconclus

ao/viewTrabalhoConclusao.jsf?popup=true\&id_trabalho=3631390. Acesso em: 03 jan. 2021.

SANTOS, Maria Aparecida Siqueira. As políticas educacionais e seus impactos na educação indígena: um estudo nas comunidades pertencentes ao município de Guajará-Mirim/RO. 2014. 119 f. Dissertação (Mestrado em Educação) - Universidade Federal de Rondônia, Porto Velho, 2014. Disponível em: http://www.ppge.unir.br/ uploads/62248421/arquivos/DISSERTA_O

_MARIA_APARECIDA_SIQUEIRA_SANTOS_120172265.pd. Acesso em: 03 jan. 2021.

SECRETARIA DE ESTADO DE TURISMO. Amazônia Maranhense. Site, 2021. Disponível em: https://www. turismo.ma.gov.br/amazonia-maranhense/. Acesso em: 13 jan. 2021.

VIEIRA, Luana Robles. Escola indígena diferenciada: a experiência Yanomami no Médio Rio Negro. 2018. 158 f. Dissertação (Mestrado em Educação) - Universidade de São Paulo, São Paulo, 2018. Disponível em: https:// teses.usp.br/teses/disponiveis/48/48134/tde-28112018-144904/pt-br.php. Acesso em: 03 jan. 2021. 